\title{
CAMPOS NATIVOS E MATAS ADJACENTES DA REGIÃO DE HUMAITÁ (AM): ATRIBUTOS DIFERENCIAIS DOS SOLOS
}

\author{
Native grassland and adjacent forest at Humaitá region, Amazonas state, \\ Brazil: differential attributes of soils
}

\author{
Gilvan Coimbra Martins' ${ }^{1}$, Mozart Martins Ferreira², Nilton Curi², Antonio Carlos Tadeu Vitorino², \\ Marx Leandro Naves Silva ${ }^{2}$
}

\begin{abstract}
RESUMO
Existem no sul do Amazonas aproximadamente 560 mil hectares de campos de cerrados, distribuídos principalmente, nos municípios de Humaitá, Lábrea e Canutama. A região não é coberta por campos contínuos, mas por várias unidades isoladas entremeadas por matas. As formas de vegetação primitiva indicam ambientes peculiares, como o regime hídrico, fertilidade natural e aeração do solo. Assim, objetivou-se no presente trabalho estabelecer algumas razões da estratificação ambiental entre mata e campo nativo na região de Humaitá (AM). Para tanto, foram observados morfologicamente e amostrados 10 perfis de solos, sendo 5 perfis sob mata e 5 perfis sob campo cerrado nativo. As amostras foram coletadas nas profundidades de 0-20, 20-40 e 60-80 cm, em trincheiras. Os solos sob vegetação de campo nativo e sob mata possuem atributos químicos semelhantes e mineralógicos idênticos. A ocorrência de solos com maior profundidade efetiva, com melhor drenagem e maior volume de armazenamento de água, em associação à maior inclinação do horizonte plíntico no sentido do igarapé, aumentando o fluxo de água nesta direção, favorecem o aparecimento da vegetação de mata, enquanto que condições opostas a estas favorecem o aparecimento da vegetação de campo nativo.
\end{abstract}

Termos para indexação: Solos da Amazônia, propriedades físicas, mineralogia, horizonte plíntico.

\begin{abstract}
At the south of Amazonas state there are about 560,000 hectares of cerrado grassland which are mainly distributed in Humaitá, Lábrea and Canutama counties. The region is not covered by continuous grasslands, but by various isolated units intermixed by forests. The primitive vegetation phases indicate peculiar environments, such as the hydric regimen, natural fertility and aeration of soil. So, this work has as objective to stablish some reasons for the environmental distinction between forest and native grassland at Humaitá ( Amazonas state ) region. For that, 10 soil profiles were morphologically observed and sampled, being 5 profiles under forest and 5 profiles under native cerrado grassland. The samples were collected at 0-20, 20-40, and 60-80 cm depth, through pits. The soils under native grassland and under forest have similar chemical and identical mineralogical attributes. The occurrence of soils with greater effective depth, better dreinage and higher volume of water storage, in association with a higher inclination of the plinthic horizon in the direction of the "igarapé" (narrow riverbank between two islands or between an island and the main land), increasing the water flow in this direction, favor the forest vegetation, while opposite conditions to these ones favor the native grassland vegetation.
\end{abstract}

Index terms: Amazon's soils, physical properties, mineralogy, plinthic horizon.

(Recebido para publicação em 11 de janeiro de 2005 e aprovado em 25 de janeiro de 2006)

\section{INTRODUÇÃO}

Existem no sul do Amazonas aproximadamente 560 mil hectares de campos de cerrados, distribuídos principalmente, nos municípios de Humaitá, Lábrea e Canutama, localizados sobre a Planície Amazônica entre os rios Purus e Madeira. A região não é coberta por campos contínuos, mas por várias unidades isoladas entremeadas por matas. O relevo é próximo do tipo "tabuleiro", de pequeno desnível, com os bordos ligeiramente abaulados (BRAUN \& RAMOS, 1959).

A origem do Campo Cerrado na Amazônia ainda é bastante discutida, mas supostamente diferente das apresentadas para explicar a ocorrência do Cerrado do Brasil Central. De acordo com a teoria dos redutos florestais, durante o Pleistoceno, que vai de 2 milhões a 12 mil anos atrás, ocorreram diversas glaciações responsáveis pelo resfriamento do planeta. Na Amazônia, a temperatura média caiu pelo menos $4,5^{\circ} \mathrm{C}$. Nos períodos secos, a região era dominada por savanas e cerrados. A mata reduzia-se a pequenas "manchas" de vegetação tropical chamadas redutos (RANZI, 1993).

Solo, clima e organismos interagindo, dão a cada lugar uma fisionomia diferente - um ambiente diferente segundo, Resende \& Rezende (1983). As formas da vegetação indicam ambientes peculiares, como o regime hídrico, fertilidade natural e aeração do solo.

\footnotetext{
${ }^{1}$ Engenheiro Agrônomo, EMBRAPA Amazônia Ocidental - Rodovia Torquato Tapajós (AM-010), km 29 -69.011-970 - Manaus, AM.

2 Engenheiro Agrônomo, Departamento de Ciência do Solo da Universidade Federal de Lavras/UFLA - Cx. P. 3037 - $37.200-000$ - Lavras, MG.

${ }^{3}$ Engenheiro Agrônomo, Departamento de Ciências Agrárias da Universidade Federal do Mato Grosso do Sul/UFMS - Cx. P. 533 - $79.804-907$ Dourados, MS.
} 
Existe uma estreita relação entre o tipo de vegetação e as propriedades do solo sobre o qual essa vegetação ocorre (RESENDE et al., 1988). Estudos realizados por Spera (1995) e Spera et al. (1996) mostraram que a transição da vegetação de campo/mata está relacionada à mudança do tipo de solo e de suas propriedades físico-hídricas. Os solos sob mata são mais profundos, apresentam menor quantidade de frações grosseiras maiores que $2,00 \mathrm{~mm}$ e maior condutividade hidráulica saturada, sendo, portanto, mais permeáveis e capazes de armazenar maior volume de água no perfil. A vegetação mais exuberante, como a mata, induz maiores modificações no solo que a campestre, alterando a distribuição e dinâmica de resíduos orgânicos (RYAN \& MCGARITY, 1983), proporcionando menores perdas de nutrientes devido a maior heterogeneidade da composição florística e melhor cobertura do solo (FONSECA, 1978).

Com base no exposto, objetivou-se com presente trabalho estabelecer algumas razões da estratificação ambiental entre mata e campo nativo na região de Humaitá (AM).

\section{MATERIAL E MÉTODOS}

O município de Humaitá localiza-se ao sul do Estado do Amazonas à margem esquerda do rio Madeira, afluente da margem direita do Rio Amazonas, dista cerca de 200 $\mathrm{km}$ de Porto Velho e $675 \mathrm{~km}$ de Manaus pela Rodovia BR319 e está situado na zona fisiográfica do Rio Madeira. Limita-se com os municípios de Manicoré ao norte e ao leste, Tapauá e Canutama a oeste e Estado de Rondônia ao sul. A sede do município tem como coordenadas geográficas de centro $7^{0} 30^{\prime} 22^{\prime \prime}$ S. e 6 $3^{\circ} 01^{\prime} 15^{\prime \prime}$ W.Gr. O clima da região é do tipo $\mathbf{A m}$, segundo Köppen, isto porque a precipitação anual varia de 2250 a $2750 \mathrm{~mm}$, com estação seca de pequena duração (mês de julho). A temperatura média anual varia de $24^{\circ} \mathrm{C}$ a $26^{\circ} \mathrm{C}$, a umidade relativa do ar, bastante elevada, varia de 85 a $90 \%$ e a altitude média é de 90 metros acima do nível do mar (CARVALHO, 1986; EMBRAPA, 1997a).

A área amostrada localiza-se a $15 \mathrm{Km}$ de Humaitá no lado direito da BR-319, no sentido Humaitá - Porto Velho, sob a coordenada geográfica de $7^{0} 37^{\prime} \mathrm{S}$. e $63^{\circ} 05^{\prime}$ W.Gr. (Figura 1). O material de origem dos solos é representado por sedimentos da Formação Solimões. Os perfis distam entre si em cada ambiente (campo nativo ou mata) aproximadamente 200 metros e entre ambientes 2 $\mathrm{km}$. Foram amostrados 10 perfis, sendo 5 perfis sob mata e 5 perfis sob campo cerrado nativo. As amostras foram coletadas nas profundidades de 0-20, 20-40 e 60-80 cm, em trincheiras.

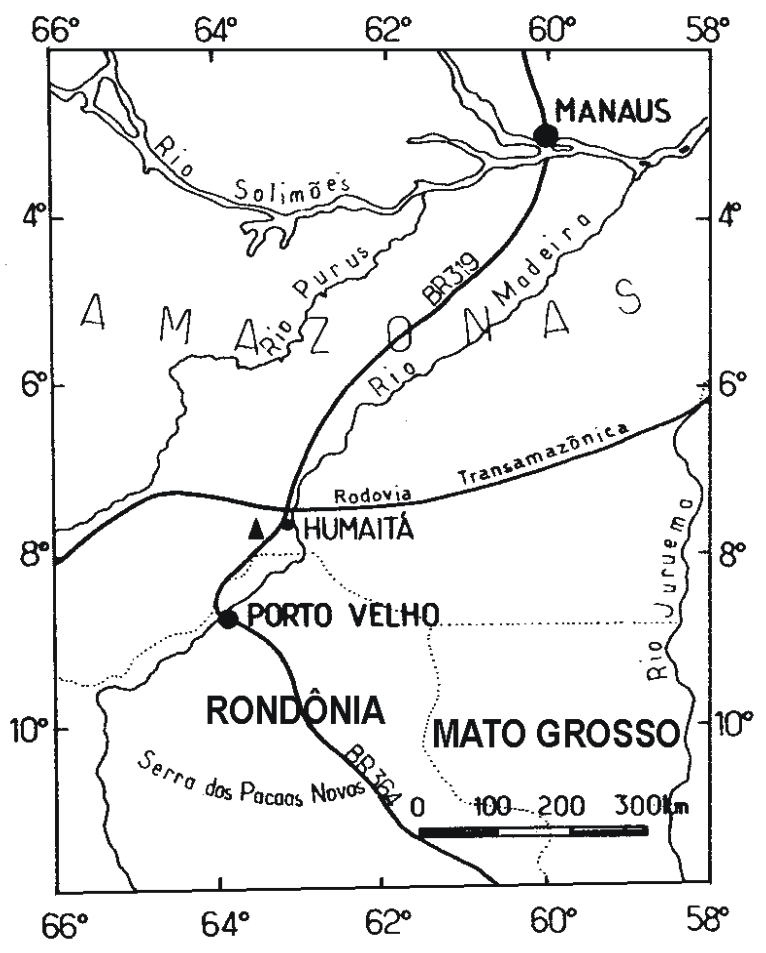

FIGURA 1 - Mapa com detalhes do sul do estado do Amazonas e Estados limítrofes ( $\boldsymbol{\Delta}=$ local de amostragem dos perfis de solos).

A mineralogia qualitativa da fração argila desferrificada foi avaliada com base nos difratogramas obtidos em aparelho de raios-X, munido com tubo de cobalto, a partir de lâminas orientadas e a fração silte pelo método do pó.

A granulometria foi feita após agitação mecânica e dispersão química com $\mathrm{NaOH} 0,1 \mathrm{~N}$ pelo método da pipeta (DAY, 1965). A densidade de partículas (Dp) foi determinada pelo método do balão volumétrico com álcool etílico (EMBRAPA, 1997b). Para a determinação da densidade do solo (Ds), foram utilizadas amostras indeformadas, conforme Blake \& Hartge (1986).

A estabilidade de agregados, expressa pelo seu diâmetro médio geométrico (DMG), foi avaliada por peneiramento via úmida, em dispositivo oscilatório vertical dentro de recipientes com água, conforme Kemper \& Chepil (1965) e Yoder (1936).

O volume total de poros (VTP) foi calculado de acordo com a fórmula de Vomocil (1965): VTP(\%)=(1-Ds/ Dp)x 100. Macroporosidade e microporosidade foram obtidas a partir de amostras com estrutura indeformada e 
colocadas em unidade de sucção submetidas à tensão de -0,006 MPa, conforme Grohmann (1960) e Oliveira (1968). A condutividade hidráulica do solo saturado (Ks) foi determinada por meio de permeâmetro de carga constante, seguindo metodologia descrita por Lima (1987), com o uso de amostras indeformadas previamente saturadas.

$\mathrm{O}$ pH foi determinado na relação solo:água de 1:2,5, $\mathrm{Al}, \mathrm{Ca}$ e $\mathrm{Mg}$ trocáveis foram extraídos com $\mathrm{KCl} 1 \mathrm{~N}, \mathrm{~K}$ e $\mathrm{P}$ por Mehlich-1 e H + Al com solução de acetato de cálcio $1 \mathrm{~N}$ a pH 7,0 (EMBRAPA, 1997b). O carbono orgânico foi determinado por meio de digestão com bicromato de potássio, segundo Defelipo \& Ribeiro (1981) e transformado em teor de matéria orgânica multiplicando-se pela constante 1,724 .

$\mathrm{O}$ delineamento experimental utilizado foi $\mathrm{o}$ inteiramente casualizado (DIC), com cinco repetições, sendo as profundidades estruturadas em faixas.

Os atributos foram submetidos à análise de variância, utilizando-se o programa SISVAR (FERREIRA, 2000) e PROC GLM do programa SAS Statistical Analysis System (SAS INSTITUTE, 1987). Aos resultados significativos aplicou-se o teste de Scott-Knott a 5\% de probabilidade.

\section{RESULTADOS E DISCUSSÃO}

Os solos dos ambientes de mata e campo nativo apresentam a mesma mineralogia, com predomínio da caulinita (Figura 2). Ocorre também a presença de material 2:1 não expansivo (mica), em consonância com o atributo diagnóstico argila de atividade alta (EMBRAPA, 1999). Estudos de Carvalho (1986) e Volkoff \& Cerri (1981) em áreas próximas àquelas do presente estudo, indicaram a presença de vermiculitas e ilitas, enquanto que Braun \& Ramos (1959), verificaram a presença de haloisita.

Com relação à granulometria, observa-se que a fração silte domina nos solos dos ambientes estudados (Tabela1), enquadrando estes solos na classe textural franco-argilo-siltosa. Segundo Resende et al. (1999), a fração silte é tida como indicadora do grau de intemperização do solo ou do potencial deste em conter minerais primários facilmente intemperizáveis, isto é, de sua reserva em nutrientes. No entanto, após análise de DRX pelo método do pó desta fração (dados não apresentados), observou-se apenas presença de quartzo, fato também constatado por Volkoff \& Cerri (1981). O uso e manejo destes solos tende a ser dificultado pelos elevados teores de silte, uma vez que tal fração quando submetida à ação das gotas de chuva e ciclos alternados de umedecimento e secagem, provoca a criação de uma camada selada, que dificulta a infiltração de água e emergência de plântulas (RESENDE et al., 1999).

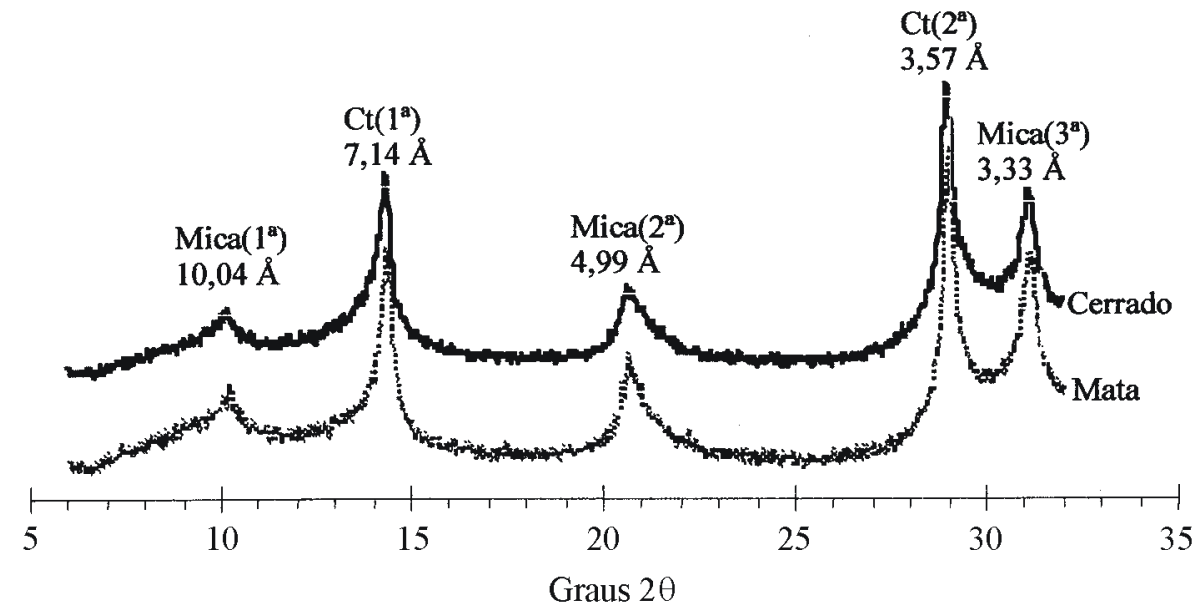

FIGURA 2 - Difratogramas de raios-X da fração argila desferrificada dos solos sob mata e campo nativo. Mi: mica; $\mathrm{Ct}$; caulinita. 
TABELA 1 - Valores médios de atributos físico-hídricos e de matéria orgânica em solos sob mata e campo nativo da região de Humaitá - AM, em três profundidades.

\begin{tabular}{|c|c|c|c|c|c|c|}
\hline \multirow{3}{*}{ Atributo } & \multirow{2}{*}{\multicolumn{3}{|c|}{$\begin{array}{c}\text { Mata } \\
\text { Profundidade }(\mathrm{cm})\end{array}$}} & \multirow{2}{*}{\multicolumn{3}{|c|}{$\begin{array}{c}\text { Campo nativo } \\
\text { Profundidade }(\mathrm{cm})\end{array}$}} \\
\hline & & & & & & \\
\hline & 0 - 20 & $20-40$ & $60-80$ & 0 - 20 & $20-40$ & $60-80$ \\
\hline Areia $\left(\mathrm{g} \cdot \mathrm{kg}^{-1}\right)$ & 160 & 130 & 110 & 180 & 130 & 120 \\
\hline Silte $\left(\mathrm{g} . \mathrm{kg}^{-1}\right)$ & 560 & 520 & 470 & 640 & 600 & 550 \\
\hline $\operatorname{Argila}\left(\mathrm{g} . \mathrm{kg}^{-1}\right)$ & 280 & 350 & 420 & 180 & 270 & 330 \\
\hline $\operatorname{Ds}\left(\mathrm{g} \cdot \mathrm{cm}^{-3}\right)$ & $1,21 \mathrm{~b}$ & $1,31 b$ & $1,48 \mathrm{a}$ & $1,24 b$ & $1,44 \mathrm{a}$ & $1,49 \mathrm{a}$ \\
\hline $\mathrm{DMG}(\mathrm{mm})$ & $1,80 \mathrm{~A}$ & $1,41 \mathrm{~B}$ & $1,27 \mathrm{~B}$ & $1,87 \mathrm{~A}$ & $1,81 \mathrm{~A}$ & $1,86 \mathrm{~A}$ \\
\hline $\mathrm{Ks}\left(\mathrm{mm} \cdot \mathrm{h}^{-1}\right)$ & 88,99 & 51,20 & 28,18 & 73,40 & 14,95 & 39,10 \\
\hline $\operatorname{VTP}(\%)$ & $51,88 \mathrm{a}$ & $48,72 \mathrm{a}$ & $42,96 \mathrm{~b}$ & $50,58 \mathrm{a}$ & $44,10 \mathrm{~b}$ & $43,80 \mathrm{~b}$ \\
\hline Macrop.(\%) & $10,99 a$ & $12,87 \mathrm{a}$ & $7,24 \mathrm{~b}$ & $10,23 \mathrm{a}$ & $11,06 \mathrm{a}$ & $5,70 \mathrm{~b}$ \\
\hline Micropor.( \%) & $40,88 \mathrm{a}$ & $35,86 b$ & $35,73 b$ & $40,15 \mathrm{a}$ & $33,00 \mathrm{~b}$ & $38,10 \mathrm{a}$ \\
\hline Mat orgânica $\left(g \cdot \mathrm{kg}^{-1}\right)$ & $22,6 \mathrm{Aa}$ & $8,4 \mathrm{Ab}$ & $2,0 \mathrm{Ac}$ & $17,0 \mathrm{Ba}$ & $3,4 \mathrm{Ab}$ & $1,6 \mathrm{Ab}$ \\
\hline
\end{tabular}

Médias seguidas pela mesma letra minúscula (dentro de um mesmo ambiente) e maiúscula (dentro da mesma profundidade entre ambientes) não diferem entre si , pelo teste de Scott-Knott a 5\%.

Observa-se na Tabela 1 que ocorre um aumento significativo da densidade do solo em profundidade nos dois ambientes. Maiores teores de matéria orgânica na camada superficial implicam em menores valores para densidade do solo.

O DMG é igual nos horizontes superficiais, porém, em profundidade é significativamente maior no campo do que na mata. Esses resultados são reflexos da presença da plintita nas profundidades amostradas das áreas de campo.

Os valores médios das variáveis VTP, macro e microporosidade apresentaram a mesma tendência, ou seja, decresceram significativamente em profundidade (Tabela1), sendo praticamente iguais entre os ambientes, porém, a macroporosidade foi sempre superior na mata.

A Ks não foi afetada significativamente, tanto para ambientes quanto para profundidades. Essas diferenças provavelmente não foram detectadas por apresentarem alta variância devido à grande variabilidade espacial existente $(\mathrm{CV}=105 \%)$, estando esses resultados de acordo com os encontrados nos estudos de Castro (1995) e José (2000). No entanto, os valores médios da condutividade são maiores na mata $\left(56,46 \mathrm{~mm} \mathrm{~h}^{-1}\right)$ em relação ao campo nativo $\left(42,48 \mathrm{~mm} \mathrm{~h}^{-1}\right)$, fato que deve proporcionar maior permeabilidade aos solos sob mata, com conseqüências diretas sobre um maior volume de armazenamento de água devido seus solos apresentarem maior profundidade efetiva. Trabalhando com ambientes de mata e campo, Spera et al. (1996) também encontraram maiores valores de condutividade hidráulica saturada em ambiente de mata.
Os atributos químicos dos solos estudados estão apresentados na Tabela 2. A fertilidade natural dos solos sob mata e campo nativo é muito baixa. De acordo com Falesi (1972) e Schubart et al. (1984), os solos sob mata tropical apresentam baixos teores de nutrientes, em função da ciclagem condicionada pela rápida decomposição da matéria orgânica, fazendo com que os nutrientes se concentrem na biomassa e não no solo, constituindo um mecanismo de conservação de nutrientes, mantendo a exuberância da floresta Amazônica. No tocante aos solos sob campo, seus baixos índices de fertilidade natural têm sido exaustivamente registrados na literatura (BRASIL, 1978; CARVALHO, 1986; EMBRAPA, 1983).

Os teores de $\mathrm{Al}$ e $\mathrm{H}+\mathrm{Al}$ são significativamente superiores na mata, nas camadas superficiais, em relação ao campo nativo, enquanto que na profundidade de $60-80 \mathrm{~cm}$ são estatisticamente iguais, contrapondo neste caso, a teoria do oligotrofismo relatada por Alvim (1954) e Goodland (1971), que consideram a presença tóxica do alumínio como fator ecológico de grande efeito sobre a ocorrência da vegetação dos campos cerrados. Estudos de Gualberto et al. (1987) confirmam os resultados aqui obtidos.

A Figura 3, mostra-se o perfil esquemático da área de estudo dos solos recobertos por mata e campo nativo na região de Humaitá-AM. O solo recoberto por mata foi classificado como Argissolo Vermelho-Amarelo Alumínico típico (PVAa) e o solo recoberto por campo nativo foi classificado como Plintossolo Argilúvico Alumínico típico (FTa) (EMBRAPA, 1999).

Ciênc. agrotec., Lavras, v. 30, n. 2, p. 221-227, mar./abr., 2006 
TABELA 2 - Valores médios de atributos químicos em solos sob mata e campo nativo da região de Humaitá - AM, em três profundidades.

\begin{tabular}{|c|c|c|c|c|c|c|}
\hline \multirow{3}{*}{ Atributo } & \multicolumn{3}{|c|}{ Mata } & \multicolumn{3}{|c|}{ Campo nativo } \\
\hline & \multicolumn{3}{|c|}{ Profundidade $(\mathrm{cm})$} & \multicolumn{3}{|c|}{ Profundidade $(\mathrm{cm})$} \\
\hline & 0 - 20 & $20-40$ & $60-80$ & $0-20$ & $20-40$ & $60-80$ \\
\hline $\mathrm{pH} \mathrm{H}{ }_{2} \mathrm{O}$ & $4,38 \mathrm{Bb}$ & $4,54 \mathrm{Bb}$ & $4,72 \mathrm{Aa}$ & $4,68 \mathrm{Aa}$ & $4,76^{\mathrm{A} a}$ & $4,52 \mathrm{Aa}$ \\
\hline $\mathrm{P}\left(\mathrm{mg} \mathrm{dm}^{-3}\right)$ & 1,2 & 1,0 & 1,0 & 1,0 & 1,0 & 1,0 \\
\hline $\mathrm{K}\left(\mathrm{mg} \mathrm{dm}^{-3}\right)$ & $26,6 \mathrm{Aa}$ & $14,2 \mathrm{Ab}$ & $8,8 \mathrm{Ab}$ & $12,8 \mathrm{Ba}$ & $6,4 \mathrm{Ba}$ & $11,6 \mathrm{Aa}$ \\
\hline $\mathrm{Ca}\left(\mathrm{cmol}_{\mathrm{c}} \mathrm{dm}^{-3}\right)$ & 0,50 & 0,48 & 0,48 & 0,38 & 0,38 & 0,40 \\
\hline $\mathrm{Mg}\left(\mathrm{cmol}_{\mathrm{c}} \mathrm{dm}^{-3}\right)$ & 0,14 & 0,16 & 0,14 & 0,16 & 0,16 & 0,18 \\
\hline $\mathrm{Al}\left(\mathrm{cmol}_{\mathrm{c}} \mathrm{dm}^{-3}\right)$ & $4,46 \mathrm{Ab}$ & $5,30 \mathrm{Ab}$ & $6,26 \mathrm{Aa}$ & $1,72 \mathrm{Bb}$ & $2,24 \mathrm{Bb}$ & $5,44 \mathrm{Aa}$ \\
\hline $\mathrm{H}+\mathrm{Al}\left(\mathrm{cmol}_{\mathrm{c}} \mathrm{dm}^{-3}\right)$ & $19,06 \mathrm{Aa}$ & $17,74 \mathrm{Aa}$ & $16,68 \mathrm{Aa}$ & $6,72 \mathrm{Bb}$ & $7,24 \mathrm{Bb}$ & $17,12 \mathrm{Aa}$ \\
\hline $\mathrm{S}\left(\mathrm{cmol}_{\mathrm{c}} \mathrm{dm}^{-3}\right)$ & 0,74 & 0,66 & 0,62 & 0,54 & 0,54 & 0,60 \\
\hline $\mathrm{t}\left(\mathrm{cmol}_{\mathrm{c}} \mathrm{dm}^{-3}\right)$ & $5,20 \mathrm{Aa}$ & $5,96 \mathrm{Aa}$ & $6,88 \mathrm{Aa}$ & $2,26 \mathrm{Bb}$ & $2,78 \mathrm{Bb}$ & $6,04 \mathrm{Aa}$ \\
\hline $\mathrm{T}\left(\mathrm{cmol}_{\mathrm{c}} \mathrm{dm}^{-3}\right)$ & $19,80 \mathrm{Aa}$ & $18,40 \mathrm{Aa}$ & $17,30 \mathrm{Aa}$ & $7,26 \mathrm{Bb}$ & $7,78 \mathrm{Bb}$ & $17,72 \mathrm{Aa}$ \\
\hline $\mathrm{m}(\%)$ & $86,46 \mathrm{Aa}$ & $88,66 \mathrm{Aa}$ & $90,82 \mathrm{Aa}$ & $74,96 \mathrm{Bc}$ & $79,60 \mathrm{Bb}$ & $89,14 \mathrm{Aa}$ \\
\hline $\mathrm{V}(\%)$ & $3,52 \mathrm{Ba}$ & $4,00 \mathrm{Ba}$ & $4,24 \mathrm{Aa}$ & $8,02 \mathrm{Aa}$ & 7,70Aa & $3,80 \mathrm{Ab}$ \\
\hline
\end{tabular}

Médias seguidas pela mesma letra minúscula (dentro de um mesmo ambiente) e maiúscula (dentro da mesma profundidade entre ambientes) não diferem entre si, pelo teste de Scott-Knott a 5\%.

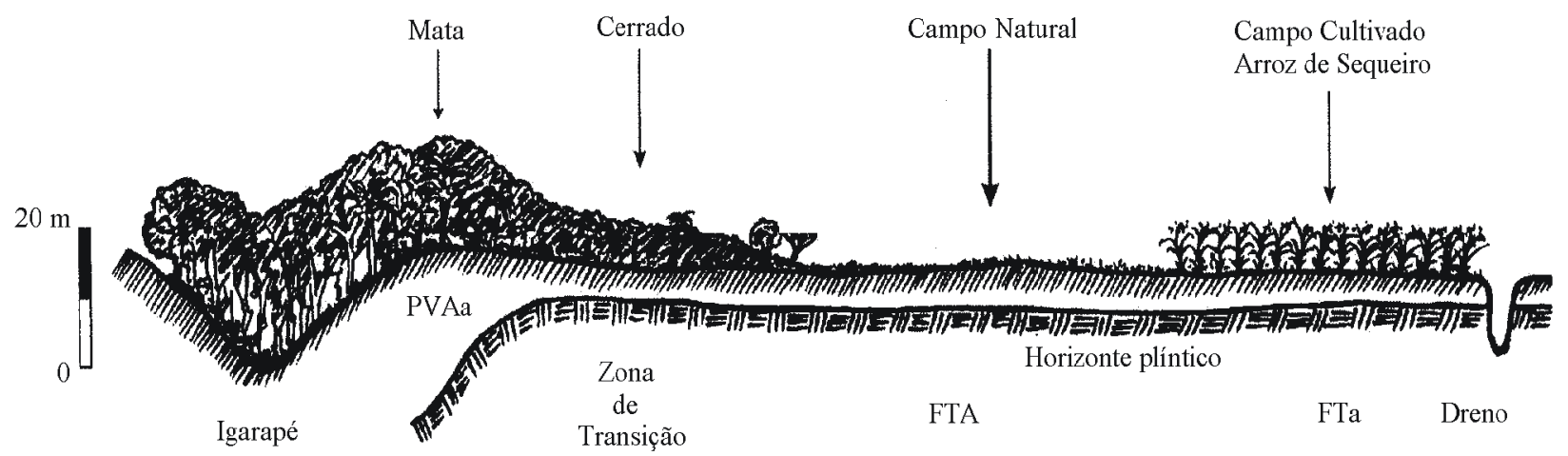

FIGURA 3 - Perfil esquemático da área de estudo mostrando a distribuição dos solos Argissolo Vermelho-Amarelo Alumínico típico (PVAa), Plintossolo Argilúvico Alumínico típico (FTa) e suas relações com o relevo, vegetação e horizonte plíntico. Fonte: Adaptado de Braun \& Ramos (1959).

Comparativamente ao campo nativo observa-se que o solo sob mata possui perfil com maior profundidade efetiva, refletindo seu maior grau de desenvolvimento, com melhor drenagem. No campo nativo, o horizonte plíntico se inicia entre 30 e $40 \mathrm{~cm}$ no presente estudo.

Se por um lado as diferenças dos atributos químicos dos solos sob mata e sob campo nativo não foram suficientes para afetar a vegetação, por outro, os atributos morfológicos e físico-hídricos dos solos sob vegetação de mata, manifestados pela maior profundidade efetiva do perfil, maior volume de armazenamento e infiltração de água, além da maior inclinação do horizonte plíntico no sentido do igarapé (Figura 3), aumentando o fluxo de água nesta direção, favorecem o desenvolvimento da vegetação de mata. A simples presença do horizonte plíntico mais superficial nos solos sob campo nativo não explica a ocorrência deste tipo de vegetação, pois há vários registros de vegetação florestal sobre solos com plintita iniciandose na profundidade de $40 \mathrm{~cm}$ (EMBRAPA, 1983) ou menor (BRASIL, 1978). 


\section{CONCLUSÕES}

a) Os solos sob vegetação de campo nativo e sob mata possuem atributos químicos semelhantes e mineralógicos idênticos.

b) A ocorrência de solos com maior profundidade efetiva, com melhor drenagem e maior volume de armazenamento de água, em associação à maior inclinação do horizonte plíntico no sentido do igarapé, aumentando o fluxo de água nesta direção, favorecem o aparecimento da vegetação de mata, enquanto que condições opostas a estas favorecem o aparecimento da vegetação de campo nativo.

\section{REFERÊNCIAS BIBLIOGRÁFICAS}

ALVIM, P. de T. Teoria sobre a formação dos campos cerrados. Revista Brasileira de Geografia, Rio de Janeiro, v. 16 , n. 4 , p. 496-498, out./dez. 1954.

BLAKE, G. R.; HARTGE, K. H. Bulk density. In: KLUTE, A. Methods of soil analysis: physical and mineralogical methods. Madison: American Society of Agronomy, 1986. p. 363-375.

BRASIL. Ministério das Minas e Energia. Projeto Radambrasil, folha SB. 20, Purus. Rio de Janeiro, 1978. 561 p.

BRAUN, E. H. G.; RAMOS, J. R. de A. Estudo agroecológico dos campos Puciarí-Humaitá (Estado do Amazonas e Território Federal de Rondônia). Revista Brasileira de Geografia, Rio de Janeiro, v. 21, n. 4, p. 443497, out./dez. 1959.

CARVALHO, A. M. Caracterização física, química e mineralógica dos solos do município de Humaitá-AM. 1986. 166 f. Tese (Livre Docência) - Universidade do Estado de São Paulo, Botucatu, 1986.

CASTRO, O. M. Comportamento físico e químico de um Latossolo Roxo em função de seu preparo na cultura do milho (Zea mays L.). 1995. 174 f. Tese (Doutorado em Solos e Nutrição de Plantas) - Escola Superior de Agricultura de Luiz de Queiroz, Piracicaba, 1995.

DAY, P. R. Particle fractionation and particle-size analysis. In: BLACK, C. A. (Ed.). Methods of soil analysis. Madison: ASA, 1965. p. 545-566.
DEFELIPO, B. V.; RIBEIRO, A. C. Análise química do solo. Viçosa: UFV, 1981. 17 p. (Boletim de extensão, 29).

EMPRESA BRASILEIRA DE PESQUISA AGROPECUÁRIA. Sistema brasileiro de classificação de solos. Rio de Janeiro, 1999. 412 p. (EMBRAPA SOLOS/ SPI).

EMPRESA BRASILEIRA DE PESQUISA AGROPECUÁRIA. Secretaria de Assuntos Estratégicos (SAE). Estudo de viabilidade agrícola de cerrados do Amazonas. Brasília, DF, 1997a. 91 p. (EMBRAPA/BNDES. Relatório técnico).

EMPRESA BRASILEIRA DE PESQUISA AGROPECUÁRIA. Serviço Nacional de Levantamento e Conservação de Solos. Manual de métodos de análise de solo. 2. ed. Rio de Janeiro: Ministério da Agricultura, 1979b. $212 \mathrm{p}$.

EMPRESA BRASILEIRA DE PESQUISA AGROPECUÁRIA. Serviço Nacional de Levantamento e Conservação de Solos. Levantamento exploratório dos solos que ocorrem ao longo da rodovia Manaus-Porto Velho. Rio de Janeiro: Ministério da Agricultura, 1983. $97 \mathrm{p}$.

FALESI, I. C. Solos da rodovia Transamazônica. Belém: IPEAN, 1972. 153 p. (Boletim técnico, 55).

FERREIRA, D. F. Análises estatísticas por meio do SISVAR (Sistema para Análise de Variância) para Windows v. 4.0. In: REUNIÃO ANUAL DA REGIÃO BRASILEIRA DA SOCIEDADE INTERNACIONAL DE BIOMETRIA, 45., 2000, São Carlos, SP. Anais... São Carlos: UFSCar, 2000. p. 255-258.

FONSECA, S. da. Propriedades físicas, químicas e microbiológicas de um Latossolo Vermelho-Amarelo sob eucalipto, mata natural e pastagem. 1978. 78 f. Dissertação (Mestrado em Solos e Nutrição de Plantas) - Universidade Federal de Viçosa, Viçosa, 1978.

GOODLAND, R. Oligotrofismo e alumínio no cerrado. In: SIMPÓSIO SOBRE O CERRADO, 3., 1971, São Paulo. Anais... São Paulo: USP, 1971. p. 44-60. 
GROHMANN, F. Distribuição e tamanho de poros em três tipos de solos do Estado de São Paulo. Bragantia, Campinas, v. 19, n. 21, p. 319-329, abr. 1960.

GUALBERTO, V.; RESENDE, M.; CURI, N. Química e mineralogia de Latossolos, com altos teores de ferro, da Amazônia e do Planalto Central. Revista Brasileira de Ciência do Solo, Campinas, v. 11, p. 245-252, 1987.

JOSÉ, M. R. Atributos físicos de Latossolo VermelhoAmarelo submetido a diferentes sistemas de manejo na região de Lavras-MG. 2000. 58 p. Dissertação (Mestrado em Solos e Nutrição de Plantas) - Universidade Federal de Lavras, Lavras, 2000.

KEMPER, W. D.; CHEPIL, W. S. Size distribuition of aggregates. In: BLACK, C. A. Methods of soil analysis, physical and mineralogical properties including statistics of measurement and sampling: part 1. Madison: American Society of Agronomy, 1965. p. 499-510. (Agronomy, 9).

LIMA, J. M. de. Relação entre erosão, teor de ferro, parâmetros físicos e mineralógicos de solos da região de Lavras - MG. 1987. 86 f. Dissertação (Mestrado em Solos e Nutrição de Plantas) - Universidade Federal de Lavras, Lavras, 1987.

OLIVEIRA, L. B. de. Determinação de macro e microporosidade pela "mesa de tensão" em amostras de solo com estrutura indeformada. Pesquisa Agropecuária Brasileira, Brasília, v. 3, n. 1, p. 197-200, 1968.

RANZI, A. A paleofauna da Amazônia indica áreas de pastagem com pouca cobertura vegetal. Ciência Hoje, Rio de Janeiro, v. 16, n. 93, p. 48-51, set./out. 1993.

RESENDE, M.; CURI, N.; REZENDE, S. B.; CORRÊA, G. F. Pedologia: base para distinção de ambientes. Viçosa: NEPUT, 1999. 367 p.

RESENDE, M.; CURI, N.; SANTANA, D. P. Pedologia e fertilidade do solo: interações e aplicações. Brasília, DF: Ministério da Educação; Lavras: ESAL; Piracicaba: POTAFOS, 1988. $81 \mathrm{p}$.
RESENDE, M.; REZENDE, S. B. Levantamento de solos: uma estratificação de ambientes. Informe Agropecuário, Belo Horizonte, v. 9, n. 105, p. 3-25, set. 1983.

RYAN, P. J.; McGARITY, J. W. The nature and spatial variability of soil properties adjacent to large forest Eucalyptus. Soil Science Society of America Journal, Madison, v. 44, n. 2, p. 286-292, Mar./Apr. 1983.

SAS INSTITUTE. SAS system for elementary statistical analysis. Cary, 1987. 416 p.

SCHUBART, H. O. R.; FRANKEN, W.; LUIZÃO, F. J. Uma floresta sobre solos pobres. Ciência Hoje, Rio de Janeiro, v. 2, n. 10, p. 26-32, jan./fev. 1984.

SPERA, S. T. Inter-relações entre propriedades físico-hídricas do solo e a ocorrência de vegetação de mata e campo adjacentes no Alto Rio Grande (MG). 1995. 78 f. Dissertação (Mestrado em Solos e Nutrição de Plantas) - Universidade Federal de Lavras, Lavras, 1995.

SPERA, S. T.; FERREIRA, M. M.; CURI, N. Inter-relações entre propriedades físico-hídricas do solo e a ocorrência de vegetação de mata e campo adjacentes no Alto Rio Grande (MG). Ciência e Agrotecnologia, Lavras, v. 20, n. 2, p. 178-182, abr./jun. 1996.

VOLKOFF, B.; CERRI, C. C. Húmus em solos da floresta Amazônica na região do rio Madeira. Revista Brasileira da Ciência do Solo, Campinas, v. 5, n. 1, p. 15-21, jan./abr. 1981.

VOMOCIL, J. A. Porosity. In: BLACK, C. A. Methods of soil analysis: physical and mineralogical properties, including statistics of measurement and sampling. Madison: American Society of Agronomy, 1965. p. 299314.

YODER, R. E. A direct method of aggregate analysis of soil and study of the physical nature of erosion losses. Journal of American Society Agronomy, Madison, v. 28, n. 1, p. 337-351, Jan. 1936. 